\title{
Analysis of Enamel Rod End Pattern at Different Levels of Enamel and its Significance in Ameloglyphics
}

Manjunath $\mathrm{K}^{1 *}$ and Sivapathasundharam $\mathbf{B}^{*}$

${ }^{1}$ Department of Oral and Maxillofacial Pathology, Farooqia Dental College and Hospital, Mysore, Karnataka, India

${ }^{2}$ Department of Oral and Maxillofacial Pathology, Meenakshi Ammal Dental College and Hospital, Chennai, Tamilnadu, India

\begin{abstract}
The aim of this study is to determining the thickness of enamel showing similar enamel rod end patterns, and extrapolating our study results to estimate the duration of time takes to change into the subsequent pattern due to in vivo brushing and its significance in ameloglyphics. Eighteen maxillary left first premolars were used in this study. Of these, three teeth were used to select appropriate abrasive paper among 80-, 400-, 600-grit silicon carbide abrasive papers and five teeth were used to check reliability of the selected abrasive paper. Ten teeth were used to analyze enamel rod end patterns. The patterns were analyzed at an interval of $1 \mu \mathrm{m}$ thickness of enamel from the tooth surface till the change of third set of pattern to its subsequent pattern. Our study showed 600-grit silicon carbide abrasive paper abrades $1 \mu \mathrm{m}$ thickness of enamel upon one rotation in microtome. Biometric analysis of enamel rod end patterns obtained from 10 extracted teeth revealed that $10 \%, 60 \%$ and $30 \%$ of enamel rod end patterns were similar up to $3 \mu \mathrm{m}, 4 \mu \mathrm{m}$ and $5 \mu \mathrm{m}$ depth of enamel, respectively. In this study, 3-5 $\mu \mathrm{m}$ thickness of enamel showed similar enamel rod end pattern. On extrapolation our study results with earlier literature revealed that each enamel rod end pattern takes approximately 4-6 years to change into the subsequent pattern due to in vivo brushing. So, the enamel rod end pattern should record for at least every 4 years during its practical application.
\end{abstract}

Keywords: Enamel rod end patterns; Ameloglyphics; Biometrics analysis; Personal identification

\section{Introduction}

Odontogenesis is genetically modulated. The formation of enamel is a highly organized dynamic process, in which the ameloblasts lay down the enamel rods in an undulating and inter-twining path $[1,2]$. This is reflected on the outer surface of the enamel as a series of enamel rod end patterns. The study of these enamel rod end patterns is known as Ameloglyphics (amelo-enamel; glyphics-carvings) [3].

The term 'Biometrics' refer to identification techniques based on physical characteristics. They are sometimes referred to as positive identification because they are claimed to provide greater confidence that the identification is accurate [4]. To identify an individual based on biometric information, the biometric data should have characteristics like highly unique to each individual, easily transmittable, able to be acquired as un-intrusively as possible and distinguishable by humans without much special training [5]. In 1998 Neurotechnologija developed biometric software known as Verifinger finger identification software for biometric system integrators [6]. Liza et al. [4] used this software for automated biometric study of Hunter Schreger bands in enamel for personal identification [4]. Manjunath et al. [3] studied enamel rod endings on tooth surface using Verifinger SDK v5.0 software and revealed the uniqueness of enamel rod patterns for personal identification [3]. They also revealed that Verifinger SDK v5.0 software was reliable software for the analysis of enamel rod end patterns [7].

Even though enamel is the hardest substance in our human body, it is always subject to both micro and macro wearing during our daily activities [8]. So, the practical implementation of ameloglyphics in forensic odontology is not clear as the depth at which each enamel rod end pattern changes to subsequent pattern is unknown, If the enamel rod end pattern of a particular person is recorded, then the period at which the enamel rod end pattern changes and duration for rerecording the enamel rod end pattern is unknown. So, in this present study the enamel rod end patterns were analyzed at an interval of 1 $\mu \mathrm{m}$ thickness of enamel from the tooth surface till the change of third set of pattern to its subsequent pattern. This helps to determine the appropriate duration of time taken to change each type of enamel rod pattern to its subsequent pattern, which in turn signifies for practical application of ameloglyphics.

\section{Materials and Methods}

Eighteen male patients of age 17-24 years who were undergoing maxillary left first premolar extraction for orthodontic purposes were selected for this study. Eighteen maxillary left first premolars were collected immediately after extraction, cleaned and dispensed in $10 \%$ formalin. Of these, three teeth were used to select appropriate abrasive paper, which abrades tooth surface of approximately $1 \mu \mathrm{m}$ thickness in microtome and five teeth were used to check reliability of the selected abrasive paper. Ten teeth were used to study enamel rod end patterns at different levels of enamel.

Dentagauge 2 digital vernier caliper was used to measure the thickness of enamel abrasion. Weswox optic MT1090A rotary microtome was used to abrade the tooth surface, $0.1 \mathrm{~mm}$ thick commercially available cellulose acetate film, commercial grade acetone solvent, $10 \%$ Orthophosphoric acid, Olympus CH 20i light microscope, Nikon 5200 digital camera, Verifinger standard SDK version 5.0 software (Neurotechnologija Company, Lithuania) were

*Corresponding author: Dr. Manjunath K, Department of Oral and Maxillofacia Pathology, Farooqia Dental College and Hospital, Mysore-570010, Karnataka, India; Tel: +91 8123431714; E-mail: janmu81@yahoo.co.in

Received March 07, 2014; Accepted June 13, 2014; Published June 20, 2014

Citation: Manjunath K, Sivapathasundharam B (2014) Analysis of Enamel Rod End Pattern at Different Levels of Enamel and its Significance in Ameloglyphics. Forensic Res 5: 235 doi:10.4172/2157-7145.1000235

Copyright: (c) 2014 Manjunath K, et al. This is an open-access article distributed under the terms of the Creative Commons Attribution License, which permits unrestricted use, distribution, and reproduction in any medium, provided the original author and source are credited. 
used for biometric analysis of enamel rod endings on the tooth surface.

Decayed tooth, hypoplastic tooth, fractured tooth, abraded/eroded tooth and restored tooth were excluded from our study.

\section{Abrasive paper selection}

In this in vitro study the tooth surface was abraded in the microtome (fixed to $4 \mu \mathrm{m}$ thickness) using 80-, 400-, 600-grit silicon carbide abrasive papers. The abrasive paper which abrades the tooth surface of approximately $1 \mu \mathrm{m}$ was selected by abrading the three different teeth.

\section{Procedure}

A vertical line was drawn at the centre of lingual and buccal surface of the teeth (parallel to the long axis of the tooth). Then, a horizontal line was drawn at the mid-third area passing across the vertical line on the lingual and buccal surfaces. The Point of intersection was noted and considered as the distance of measurement. Thickness of the tooth was measured using a digital vernier caliper and measurement was noted a (Figure 1). The tooth was mounted in a block of dental plaster and fixed to the paraffin block holder of the microtome so that the tooth surface is parallel to the abrasive paper, which was mounted in the knife table of the microtome (Figure 2). The tooth surface was abraded for 10 rotations in the microtome. The amount of surface abraded was measured using the digital vernier caliper and measurement was noted b. Difference between the width of the tooth as measured initially (a) and after abrasion (b) gives the amount of tooth abraded by respective abrasive paper. Then, the number of rotations necessary for abrading 1 $\mu \mathrm{m}$ thickness of enamel was calculated.

\section{Results}

80-grit silicon carbide abrasive paper abrades $50 \mu \mathrm{m}$ thickness of enamel in 10 rotations, then one rotation abrades $5 \mu \mathrm{m}$ thickness of enamel. 400-grit silicon carbide abrasive paper abrades $30 \mu \mathrm{m}$ thickness of enamel in 10 rotations, and then one rotation abrades $3 \mu \mathrm{m}$ thickness of enamel. 600-grit silicon carbide abrasive paper abrades 10 $\mu \mathrm{m}$ thickness of enamel in 10 rotations, and then one rotation abrades $1 \mu \mathrm{m}$ thickness of enamel.

Since 600-grit silicon carbide abrasive paper abrades $1 \mu \mathrm{m}$ of enamel in one rotation in microtome, it was selected for our study.

In order to check the reliability of 600-grit silicon carbide abrasive paper in abrading $1 \mu \mathrm{m}$ thickness of enamel in one rotation in microtome, the procedure was repeated in five different teeth. The

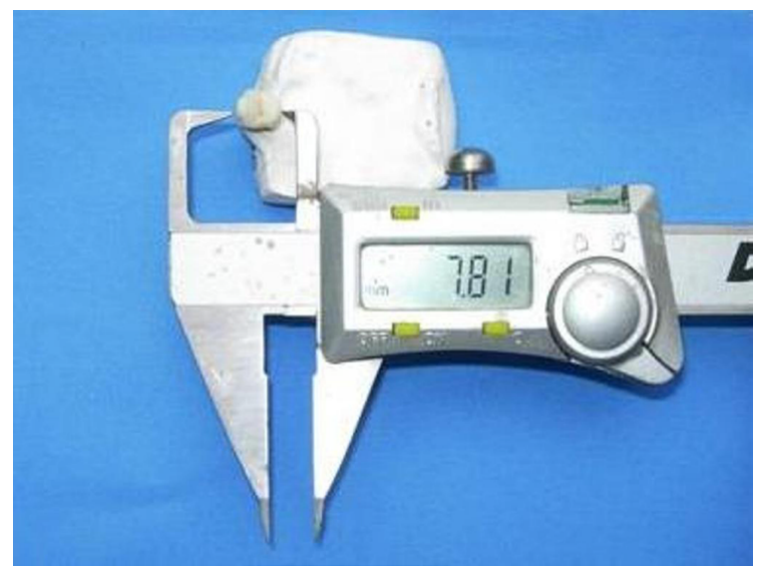

Figure 1: Thickness of tooth measured using digital vernier caliper.

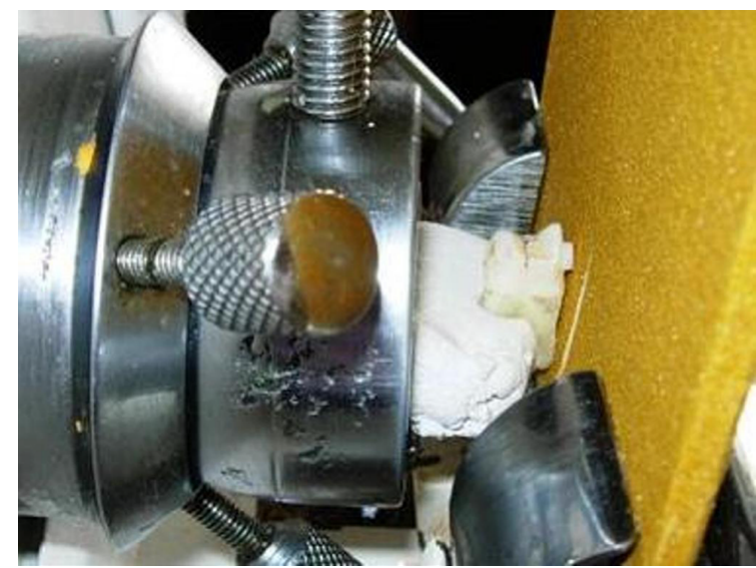

Figure 2: Tooth abraded using rotary microtome.

results confirmed that 600 -grit silicon carbide abrasive paper abrades 1 $\mu \mathrm{m}$ thickness of enamel upon one rotation in microtome.

\section{Analysis of enamel rod end patterns at different levels of enamel}

All 10 extracted teeth collected from 10 different individuals were cleaned and polished. In order to avoid error in positioning the acetate film over recording area during serial recordings, the buccal surface of the tooth was ground using an aerotor hand piece except a circular area in the mid-third measuring approximately $0.5 \mathrm{~cm}^{2}$ in diameter. Palatal surface of the tooth was flattened parallel to the long axis of the tooth in order to avoid error during measurement using digital vernier caliper. Unground circular area on buccal surface of the tooth was conditioned using $10 \%$ orthophosphoric acid for 20 seconds, then washed with water and dried. A thin layer of acetone was applied over a small piece of cellulose acetate film and placed immediately over the conditioned surface of the tooth without any finger pressure for 15 minutes. The acetone dissolves a layer of cellulose acetate and the dissolute settles down along the irregularities on the enamel surface. The film was gently peeled after 15 minutes. The peeled strip was placed on the clear glass slide and observed under the Olympus $\mathrm{CH} 20 \mathrm{i}$ light microscope. Photomicrograph of the imprint was obtained at $40 \mathrm{X}$ magnification using Nikon 5200 digital camera in 1.4X digital zoom. The photomicrograph was then cropped at the centre to $2000 \times 1500$ pixels dimension using Microsoft picture manager software.

The photomicrograph was subjected to Verifinger standard SDK v 5.0 software for obtaining enamel rod end patterns and biometric analysis.

Enamel rod end patterns are obtained at a different levels of enamel by abrading it using 600-grit silicon carbide abrasive paper i.e., at an interval of $1 \mu \mathrm{m}$ each, till the third set of enamel rod end pattern changes to subsequent pattern (Figure 3 ).

This procedure was repeated as described above in all 10 different teeth and results were tabulated and analyzed.

\section{Results}

\section{Biometric analysis}

Thickness of enamel showing similar enamel rod end patterns in all 10 extracted teeth is tabulated in Table 1.

Biometric analysis of enamel rod end patterns obtained from all 10 

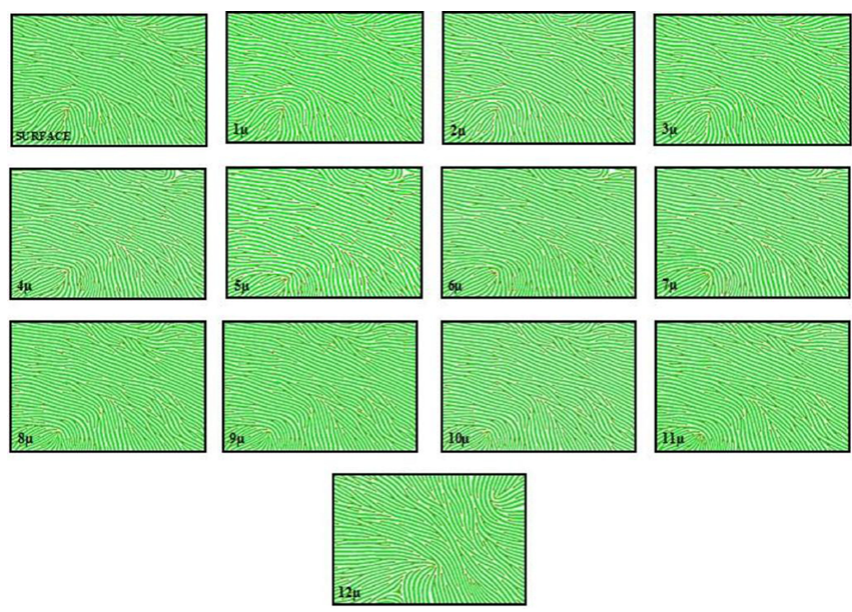

Figure 3: Enamel rod end patterns at different levels of enamel.

\begin{tabular}{|c|c|c|c|}
\hline Teeth & $\mathbf{I}(\boldsymbol{\mu})$ & II $(\boldsymbol{\mu})$ & III $(\boldsymbol{\mu})$ \\
\hline $\mathbf{1}$ & 3 & 4 & 4 \\
\hline $\mathbf{2}$ & 4 & 5 & 4 \\
\hline $\mathbf{3}$ & 3 & 4 & 4 \\
\hline $\mathbf{4}$ & 4 & 5 & 5 \\
\hline $\mathbf{5}$ & 3 & 4 & 3 \\
\hline $\mathbf{6}$ & 3 & 5 & 4 \\
\hline $\mathbf{7}$ & 2 & 4 & 3 \\
\hline $\mathbf{8}$ & 3 & 4 & 5 \\
\hline $\mathbf{9}$ & 3 & 4 & 4 \\
\hline $\mathbf{1 0}$ & 4 & 5 & 4 \\
\hline Mean & 3.2 & 4.4 & 4 \\
\hline SD & 0.63 & 0.52 & 0.67 \\
\hline
\end{tabular}

Table 1: Thickness of enamel showing similar enamel rod end patterns.

extracted I premolars reveals that $10 \%$ of enamel rod end patterns are similar up to $3 \mu \mathrm{m}$ thickness of enamel, $60 \%$ of enamel rod end patterns are similar up to $4 \mu \mathrm{m}$ thickness of enamel and $30 \%$ of enamel rod end patterns are similar up to $5 \mu \mathrm{m}$ thickness of enamel.

\section{Discussion}

The enamel rods run the whole length of enamel in an undulating and inter-twining path, which forms a specific pattern on tooth surface $[2,3]$. These enamel rod end patterns were unique for each tooth in an individual. It is specific for particular individual [3]. These enamel rod end patterns can be obtained by various methods like using cellulose acetate film, metal shadowed colloid ion film, rubber base impression materials etc. Acetate peel technique is a well-known technique for replicating surface details [3]. Fusun et al. used acetate peel technique to study dental structures in three-dimensional view, especially from fully mineralized enamel without routine decalcifying, dehydrating, sawing and mounting processes. Acetate peel technique is a simple, inexpensive, accurate and rapid method. So, this technique is selected for our study to record enamel rod end patterns from tooth surface $[9,10]$.

In the present in vitro study, first set of enamel rod end pattern change was not considered in our study because this area has been affected by abrasion due to oral hygiene habits (type of tooth brush, dentifrices, frequency of brushing and others), and personal habits of an individuals. Since second and third set of enamel rod end patterns were not affected by abrasion we consider these set of enamel rod end patterns change as standard areas to evaluate thickness of the enamel showing similar enamel rod end patterns. $10 \%, 60 \%$ and $30 \%$ of enamel rod end patterns were similar up to $3 \mu \mathrm{m}, 4 \mu \mathrm{m}$ and $5 \mu \mathrm{m}$ depth of enamel respectively.

Lambrechts et al. and Joiner et al concluded that 0.4-0.8 $\mu \mathrm{m}$ thickness of enamel abrades annually due to in vivo brushing $[11,12]$. In the present study, 3-5 $\mu \mathrm{m}$ thickness of enamel showed similar enamel rod end pattern. On extrapolation our study results confirm with Lambrechts et al and Joiner et al in situ model study, which reveals that each enamel rod end pattern takes approximately 4-6 years to change into the subsequent pattern due to in vivo brushing. So, the enamel rod end pattern should record for atleast every 4 years during its practical application.

This study enlighten the practical application of ameloglyphics in various fields and situations, especially for individuals working in dangerous occupations such as soldiers, divers, jet pilots and people who live and travel to potentially unstable areas, where short duration analysis of enamel rod end patterns may play an important role for personal identification. However, further in vivo study is suggested to analyze enamel rod end pattern and its changes over a period of time as a result of abrasion in individuals for better application of this technique for personal identification and verification.

\section{Acknowledgement}

This study is self-funded. I would like to thank Dr. T.R.Saraswathi and $\mathrm{Dr}$. Einstein T Bertin for their support to do this study.

\section{References}

1. Boyde A (1976) Amelogenesis and the structure of enamel. Bertram Cohen Ivor R H Kramer editors. Scientific foundations of dentistry. William Heinemann Medical books Ltd: 341-343.

2. Osborn JW (1968) Evaluation of previous assessments of prism directions in human enamel. J Dent Res 47: 217-222.

3. Manjunath K, Sriram G, Saraswathi TR, Sivapathasundharam B (2008) Enamel rod end patterns: a preliminary study using acetate peel technique and automated biometrics. J Forensic Odontol 1: 33-36.

4. Ramenzoni LL, Line SR (2006) Automated biometrics-based personal identification of the Hunter-Schreger bands of dental enamel. Proc Biol Sci 273: $1155-1158$

5. Shen W, Tan T (1999) Automated biometrics-based personal identification Proc Natl Acad Sci U S A 96: 11065-11066.

6. http://www.neurotechnology.com

7. Manjunath K, Sriram G, Saraswathi TR, Sivapathasundharam B, Porchelvam $S$ (2009) Reliability of automated biometrics in the analysis of enamel rod end patterns. J of Foren Dent Sci 1: 32-36.

8. Berkovitz BKB, Holland GR, Moxiham BJ, Enamel (2002) Oral Anatomy Histology and Embryology. (3rd edn) Mosby publ: 110-111.

9. Füsun A, Füsun O, Sema B, Solen K (2005) Acetate peel technique: a rapid way of preparing sequential surface replicas of dental hard tissues for microscopic examination. Arch Oral Biol 50: 837-842.

10. scott DB, Kaplan H, Wyckoff RW (1949) Replica studies of changes in tooth surfaces with age. J Dent Res 28: 31-47.

11. Lambrechts P, Braem M, Vuylsteke-Wauters M, Vanherle G (1989) Quantitative in vivo wear of human enamel. J Dent Res 68: 1752-1754.

12. Joiner A, Collins LZ, Cox TF, Pickles MJ, Weader E, et al. (2005) The measurement of enamel and dentine abrasion by tooth whitening products using an in situ model. Int Dent J 55: 194-196. 